\title{
Evaluation of Variations in Seed Vigour Characters of West African Rice (Oryza sativa L.) Genotypes Using Multivariate Technique
}

\author{
M. A. Adebisi", F. S. Okelola, M. O. Ajala, T. O. Kehinde, I. O. Daniel, O. O. Ajani \\ Department of Plant Breeding and Seed Technology, Federal University of Agriculture, Abeokuta, Nigeria. \\ Email: *adekolaitan@yahoo.com, ${ }^{*}$ mayoadebisi@yahoo.co.uk
}

Received November $5^{\text {th }}, 2012$; revised December $8^{\text {th }}, 2012$; accepted December $15^{\text {th }}, 2012$

\begin{abstract}
Seeds of 24 West African rice (Oryza sativa L.) genotypes were evaluated for seed vigour traits in the laboratory and field in two cropping seasons at the Research Farm of Federal University of Agriculture, Abeokuta, Nigeria. Seed yields of these genotypes were also determined in the field during the two seasons. Data collected on seed vigour traits were subjected to multivariate analysis including principal component analysis (PCA) and cluster analysis. The first three axes of the principal component analysis across the two seasons captured $86.34 \%$ of the total variation among the entries and identified seedling vigour index-I, seedling vigour index-II, speed of germination index, percentage germination, seedling establishment, emergence percentage and seed yield per plant as the characters contributing most to the variation. Cluster analysis classified these genotypes into four distinct groups based on germination and emergence percentages. Fifteen of the genotypes with mean values of between $60.43 \%$ and $65.18 \%$, clustered in group 1, two genotypes each with mean values of $65.71 \%$ and $58.81 \%$ and $20.11 \%$ and $29.49 \%$ clustered in groups II and IV respectively while the remaining five genotypes with mean values of between $55.19 \%$ and $55.88 \%$ clustered in group III. Hybridization of genotypes across dusters could lead to increase in heterosis in cross progenies. Those characters identified by PCA could be included in the crop improvement programme for improved seed quality within West African low land rice germplasm.
\end{abstract}

Keywords: Cluster; Euclidean Distance; Multivariate Technique; Principal Component

\section{Introduction}

Rice (Oryza sativa L.) is one of the most important cereals in the world, with a global production of 590 million tons. It is an important staple crop in Nigeria and indeed most countries. Rice is one of the most important sources of carbohydrate in the food basket of most countries of the world including Nigeria.

Multivariate statistical methods have found extensive use in summarizing and describing the inherent variation in a population of crop genotypes [1-12]. Some of the methods include principal component analysis (PCA), descriminant canonical analysis (DCA) and cluster analysis (CA). These statistical techniques identify plant characters that contribute most to the variation within a group of entries. The methods are often extended to genotype grouping in order to cluster entries that show similarity in one or more characters and thus guide in the choice of parents for hybridization $[13,14]$.

${ }^{*}$ Corresponding author.
PCA is a technique, which identifies plant characters that contribute most to the variation within a group of entries [15]. It is also a common ordinational numerical technique, which reduces the dimensions of multivariate data by removing inter-correlation among variables (characters on which units are to be compared), and enables multi-dimensional relationship to be plotted on two or three principal axes [16]. PCA chooses independent or orthogonal axes, which are minimally correlated and represents linear combination of the original characters [17]. The relative discriminating power for axes and their associated characters are measured by Eigen values and factor scores, respectively.

PCA was used as a descriptive method to show patterns of co-variation of characters among characters with 1.0 's in the diagonal of the correlation matrix, it is partitioned into components to account for a maximum amount of variance of the characters. In order to facilitate the interpretation of the result, the components can be rotated mathematically so that a given character tends to 
show its greatest contribution on a given component [18]. PCA reliably represents large distances between major groups but not between closely spaced units within the groups [19]. This technique has been used to partition observed variation in genotypes of many crops including kenaf [15]; rubber [20]; rice [10,21]; Okra [3,22]; cowpea [23] and sesame $[7,11]$.

In a study on sesame, Mponda et al. [7] reported that the first three principal axes accounted for $81.7 \%$ of the total variation in seed quality traits among 50 genotypes evaluated. He reported that the characters fall into two main groups. The group of juvenile characters contrib.utes $46.4 \%$ to the total variance as $\mathrm{PC} 1$ and the mature characters a further $28.6 \%$ as PC2. Between them, these first two components contribute $75.1 \%$ to the total variation. Similarly, Adebisi [11] also noted that the first three principal axes accounted for $57.90 \%$ of the total variation among 14 sesame genotypes and identified seed yield/ plant, capsule number/plant, capsule weight/plant, seedling vigour index, standard germination, field emergence, stress germination and seed production efficiency as components accounting for most of the variability among the sesame genotypes.

Cluster analysis is a method often extended to genotype grouping in order to cluster entries that show similarity in one or more characters and thus guide in the choice of genotypes for crop improvement [13,23]. The use of multivariate techniques to discriminate among forage varieties was discussed by Patterson and Weatherup [24]. They reported that the Euclidean distance is the simplest measure of distance and hence, discrimination among varieties but the measurement is sensitive to the scale of measurement. The cluster technique, however, shows the pattern of relationship between genotypes within a population and also classifies the genotypes into groups. The methods have been used by Akoroda [19] in yam, Ariyo [13] in okra, Alika [25] and Omokhafe and Alika [20] in rubber, Lee et al. [26] and Nassir [10] in rice, Akintobi et al. [23] in cowpea and Adebisi [11] in sesame.

The comparison of the variation patterns among rice genotypes in respect of seed quality is necessary in seeds of West African rice genotypes. Besides, literature on the varietal classification of West African rice based on seed quality (germination and emergence) is scanty. Therefore, the objective of this research work was to identify the seed vigour traits that contribute mostly to the variation in seed vigour of 24 West African genotypes across and within seasons and also to determine the extent of similarity in seed quality among the 24 West African rice genotype using germination and field emergence tests.

\section{Materials and Methods}

\subsection{Seed Source}

Seeds of 24 lowland rice genotypes (as shown in Table 1) were examined for the study. The seeds were obtained from the West African Rice Development Association (WARDA) substation in the International Institute for Tropical Agriculture (IITA), Ibadan, Nigeria.

\subsection{Experimental Sites}

Two laboratory and two field experiments were conducted in the Seed Laboratory and Teaching and Research Farms of the Federal University of Agriculture, Abeokuta, Ogun State, respectively in 2003 and 2004 cropping seasons. Seeds of each genotype were divided into two (a) one for laboratory test and (b) one for field experiment.

Table 1. The list and origin of the rice genotypes utilized for the study.

\begin{tabular}{|c|c|c|}
\hline Number & Genotypes & Origin \\
\hline 1 & WITA 8 & WARDA \\
\hline 2 & WAT 1073-B-65-2-2-2 & WARDA \\
\hline 3 & WAT 1286-B-45-2-2-3 & WARDA \\
\hline 4 & WAT 1377-119-2-3 & WARDA \\
\hline 5 & WITA I & WARDA \\
\hline 6 & BW 348-1 & Sri-Lanka \\
\hline 7 & WITA 9 & WARDA \\
\hline 8 & TOX 4004-8-1-2-3-1 & IITA \\
\hline 9 & WAT 1104-B-73-3-3-2 & WARDA \\
\hline 10 & WAT 1380-2-1 & WARDA \\
\hline 11 & WITA 7 & WARDA \\
\hline 12 & TOX 4216-25-2-3-1-3 & IITA \\
\hline 13 & WAT 1104-B-41-3-1-3 & WARDA \\
\hline 14 & WAT 1289-B-33-3-2 & WARDA \\
\hline 15 & WAT 1074-B-39-2-3-3 & WARDA \\
\hline 16 & TOX 4004-43-1-2-1 & IITA \\
\hline 17 & IR 69513-11-SRN-1-UBN-3-B & WARDA \\
\hline 18 & WAT 1059-B-51-2 & WARDA \\
\hline 19 & TOX 4303-B-3-1-1-2 & IITA \\
\hline 20 & WAT 1156-B-4-2-3-3 & WARDA \\
\hline 21 & WAT 1199-B-10 & WARDA \\
\hline 22 & WAT 1282-B-50-3-3 & WARDA \\
\hline 23 & WAT $1265-B-82-2-2-3$ & WARDA \\
\hline 24 & WAT 1073-B-74-2-3-3 & WARDA \\
\hline
\end{tabular}




\subsection{Laboratory Test}

Seed vigour tests were conducted on seed samples of the 24 genotypes of West African rice. The vigour test evaluation was carried out between November and December 2003 and repeated between May and June 2004. The study was a factorial experiment with two factors (24 varieties and two seasons). There were three replicates arranged in a completely randomized design (CRD) for each genotype.

Seed samples were investigated for seed vigour traits according to the following methods:

100 -seed weight (g) (100-SW): Weight in grammes of
100 seeds of each genotype was determined.

Germination Percentage (G\%): One hundred seeds per replicate were placed in moist filter paper in $11 \mathrm{~cm}$ diameter Petri dish. Germination count was recorded every 2 days for 8 days after sowing (DAS). The final count of germination was recorded on the 8th day according to International Seed Testing Association rules [27] and number of normal seedlings was expressed as a proportion of seeds evaluated.

Speed of Germination Index (SGI): This was calculated as described in the Association of Official Seed Analyst [28] as follows.

$$
\text { SGI }=\frac{\text { Numberof germinated seed }+\cdots+\text { Number of germinated seed }}{\text { Days of first count }+\cdots+\text { Days of final count }}
$$

Seedling Vigour Index-I (SVI-1): This was calculated from data on germination percentage and seedling growth according to Kharb et al. [29] by the formula below:

$$
\text { Seedling Vigour Index-I }=\frac{\text { Seedling length } \times \text { Germination Percentage }}{100}
$$

Seedling Vigour Index -II (SVI-II): This was calculated using the formula of Kharb et al. [29], as follows:

$$
\text { Seedling Vigour Index-II }=\frac{\text { Seedling dry weight } \times \text { Germination percentage }}{100}
$$

Energy of Germination (EG): This was obtained as the percentage of germinating seeds 3 days after planting relative to the number of seeds tested. The larger the energy of germination, the faster the rate of germination [30].

\subsection{Field Test}

The second part of the seed sample was sown in November and December 2003 and repeated in May and June 2004 as field experiments.

\subsection{Experimental Design}

The field experiment was designed as a factorial experiment with two factors ( 24 genotypes and two seasons). The field was laid out in a randomized complete block design (RCBD) with three replicates. Each genotype was sown in a $3.0 \mathrm{~m}$ long and $0.2 \mathrm{~m}$ width double row plot with a space of $1.0 \mathrm{~m}$ between each genotype and each replicate was separated by a Im alley. The field was ploughed, puddled two times and then drained during the two seasons. Seeds were sown on raised seedbeds in the field in late November, 2003 and harvested in March and April 2004 and repeated in late May 2004 and harvested in September and October 2004. The total land area was

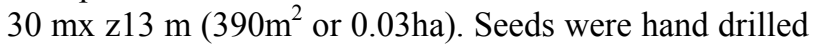
along the row while seedlings were thinned at 30 days after planting to $20 \mathrm{~cm} \times 20 \mathrm{~cm}$ plant spacing. Following thinning, a post emergence fertilizer application of N. P. K. 15-15-15 was applied by drilling at a rate of 200 $\mathrm{kgN} / \mathrm{ha}$. Urea was applied as top dressing at $65 \mathrm{~kg} / \mathrm{ha}$ at booting. The plots were weeded regularly to minimize weed infestation. Bird damage was controlled using bird scarers. Also the entire field was covered with waterproof rubber net from panicle appearance till harvesting to prevent bird attack. Rodents were checked with bamboo fence and trap constructed round the field.

The following vigour traits were determined for each of the 24 West African rice genotypes

Emergence Index (EI): This was calculated according to the formula $[11,31,32]$ as

$$
\mathrm{EI}=\sum \frac{\text { (Plants emerged in a day })(\text { Days after planting })}{\text { Plant emerged by 9DAP }}
$$

Emergence Percentage (E\%): This was calculated according to the formula

$$
\mathrm{E} \%=\frac{\text { Seedling emerged by } 9 \mathrm{DAP} \times 100}{\text { Number of seeds planted } 1}
$$

Speed of Emergence (SPE): This was calculated using the formula [33]

$$
\mathrm{SPE}=\frac{\text { Number of seedling emerged after } 5 \mathrm{DAS} \times 100}{\text { Number of seedling emerged after 11DAS } 1}
$$

Seedling Establishment (SE): This was calculated as 
the percentage of seedlings established 14 DAS relative to number of seed sown [34].

Plant Height at 30 DAS (PHT): Plant height was measured from the ground to the tip of the tallest panicle in centimeter at 30 DAS.

Seedling Dry Weight at 30 DAS (SDW): The five randomly selected plants were further dried in a hot air oven at $80^{\circ} \mathrm{C}$ for $48 \mathrm{~h}$. Dry weight was measured in gramme $(\mathrm{g})$

Seed Yield/plant (SY): Seed yield was determined as seed yield per plant and then expressed as seed yield per ha.

\subsection{Data Analysis}

All analyses were done using the SAS statistical package. Data on germination percentage, energy of germination, emergence percentage, speed of emergence and seedling establishment were analyzed after angular (arcsine) transformation of percentages.

The data were subjected to multivariate analysis consisting of the principal component analysis and hierarchical cluster analysis. The principal component analysis (PCA) was used to explain the pattern of character covariation among the genotypes. PCA was also used to identify the plant characters that contribute most to the variation within a group of entries [15] across and within seasons. For the hierarchical cluster analysis, the squared Euclidean distance between genotypes was utilized for the grouping of the genotypes (for similarity measures) using between group average linkages across and within seasons.

\section{Results}

\subsection{Principal Component Analysis (PCA)}

The extent of genetic variation in seed vigour and seed yield traits of the 24 West African rice genotypes was assessed using multivariate techniques. Principal component analysis was performed on the 24 genotypes of rice across both seasons. The results of the combined PCA across the two seasons are presented in Table 2. The arithmetic sign of the coefficient is irrelevant since a common rule of thumb for determining the significance of a trait coefficient is to treat coefficient greater than 0.3 as having a large enough effect to be considered important [35]. Traits having less than 0.2 coefficient value were considered to be of no effect to the over-all variation observed in the present study.

Also from Table 2, the results from the PCA revealed that only three of the principal components had eigen values greater than 1.0. The first three axes with eigen values of $7.86,2.17$ and 1.20 respectively, jointly accounted for $86.34 \%$ of the total variation among the genotypes. The first PC accounted for $60.47 \%$ of the variability and was related to seedling vigour index-I (0.34), seedling vigour index-II (0.34), percentage germination (0.34), speed of germination index (0.34), energy of germination (0.33), seedling establishment (0.33), seed yield (0.32) and emergence percentage $(0.32)$. The second principal component accounted for $16.68 \%$ of the total variation and was dominated by emergence index (0.66), speed of emergence (0.65) and plant dry weight at 30 DAS (0.33). The third principal component was dominated by 100 seed weight (0.73) and plant height at 30 DAS (0.56). This principal component explained an additional $9.19 \%$ of the variability. The fourth PC accounted for an additional $4.95 \%$ of the total variation and was dominated by 100 seed weight $(0.50)$, plant height $(-0.47)$ and emergence percentage $(0.36)$.

A further understanding was obtained by plotting the PC scores for individual observations in relation to the axes of PC1 and PC2 (Figure 1). The ordination of the genotypes on axes 1 and 2 has two hidden observations. Genotypes WITA 1 (E) and BW 348-1 (F) were the most distinct from the others as shown in Figure 1.

Table 2. Eigen values, percent of total variation accounted for, cumulative percent and eigen vectors of major seed vigour and seed yield traits of the first four principal components in the ordination across the two seasons.

\begin{tabular}{|c|c|c|c|c|}
\hline Traits & $\mathrm{PC} 1$ & PC 2 & PC 3 & PC 4 \\
\hline Seed yield & 0.32 & -0.07 & 0.07 & -0.29 \\
\hline Percentage germination & 0.34 & -0.05 & -0.19 & 0.14 \\
\hline 100-Seed weight & 0.13 & -0.09 & 0.73 & 0.50 \\
\hline $\begin{array}{l}\text { Speed of germination } \\
\text { index }\end{array}$ & 0.34 & 0.01 & -0.18 & 0.21 \\
\hline Seedling vigour index-I & 0.34 & -0.06 & -0.09 & 0.12 \\
\hline $\begin{array}{l}\text { Seedling vigour } \\
\text { index-II }\end{array}$ & 0.34 & -0.08 & -0.02 & 0.21 \\
\hline Energy of germination & 0.33 & -0.04 & -0.22 & 0.19 \\
\hline Emergence index & -0.06 & 0.66 & -0.00 & -0.04 \\
\hline Speed of emergence & 0.03 & 0.65 & -0.06 & 0.15 \\
\hline Emergence percentage & 0.32 & 0.04 & -0.22 & 0.36 \\
\hline Seedling establishment & 0.33 & 0.06 & -0.05 & 0.32 \\
\hline Plant height & 0.21 & 0.09 & 0.56 & 0.47 \\
\hline Seedling dry weight & 0.23 & 0.33 & 0.12 & 0.19 \\
\hline Eigen value & 7.86 & 2.17 & 1.20 & 0.64 \\
\hline Percent variance & 60.47 & 16.68 & 9.19 & 4.95 \\
\hline Cumulative variance & 60.47 & 77.15 & 86.34 & 91.29 \\
\hline
\end{tabular}

Bolded: Significant contribution to the total variations. 
Figure 2 shows the plot of the PC scores for individual observation in relation to the axes of PC1 and PC3. The ordination of the genotypes on axes 1 and 3 also had two hidden observations. Genotype WITA 1 (E) and genotype BW 348-1 (F) were the most distinct from the others.

Presented in Figure 3 is the plot of PC scores for individual observations in relation to the axes of PC2 and PC3. The ordination of the genotypes on axes 2 and 3 has one hidden observation. Genotypes WAT 1156-B-4-2-33 (T) and genotype WAT 1265-B-82-2-2-3 (W) were the most distinct from the others and they were discriminated by character related to axis 3 .

\subsection{Hierarchical Cluster Analysis}

The genotypes were classified into four groups by cluster

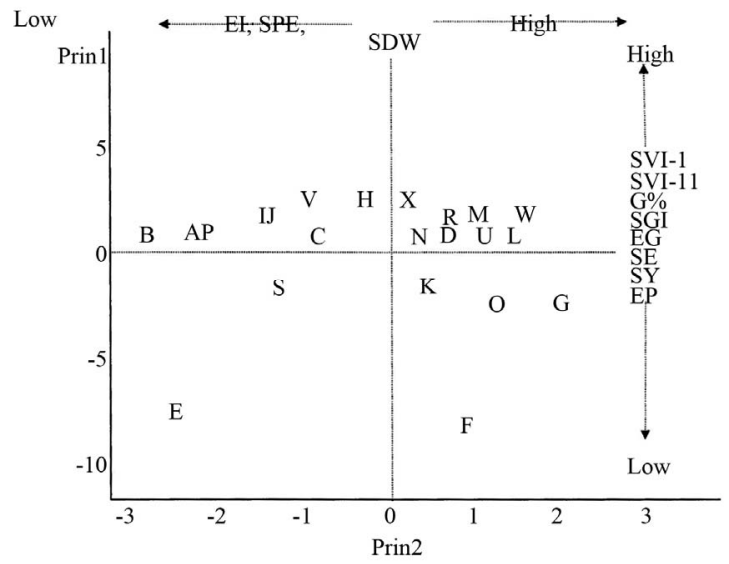

Figure 1. Biplot of the first and second principal components to show the interrelationship of seed vigour and yield traits of the 24 West African rice genotypes. Note: Letters A - X represent genotypes 1 to 24 .

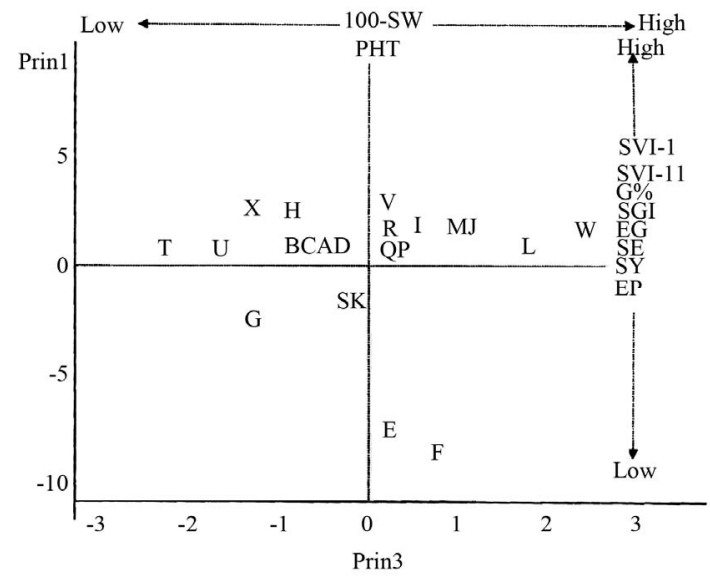

Figure 2. Biplot of the first and third principal components to show the interrelationship of seed vigour and yield traits of the 24 West African rice genotypes. Note: Letters $A-X$ represent genotypes 1 to 24 . analysis based on percentage germination and emergence percentage (Figure 4). All genotypes were distinct at an average similarity distance of 0.00 while at 2.01 they could no longer be discriminated. Genotypes included in the group I were 15 genotypes (WITA 8, WAT 1286-B45-2-2-3, WAT 1199-B-10, WAT 1073-B-65-2-2-2, WAT 1377-119-2-3, WAT 1104-B-41-3-1-3, WAT 1289-B-333-2, IR 69513-11-SRN-1-UBN-3-B, WAT 1059-B 51-2, WAT 1265-B-82-2-2-3, TOx 4004-8-1-2-3-1, WAT 1282-B-50-3-3, WAT 1104-B-73-3-3-2, WAT 1380-2-1 and WAT1073-B-74-2-3-3). Mean percentage germination and mean percentage emergence were $65.18 \%$ and $60.43 \%$ respectively. Group II included two genotypes

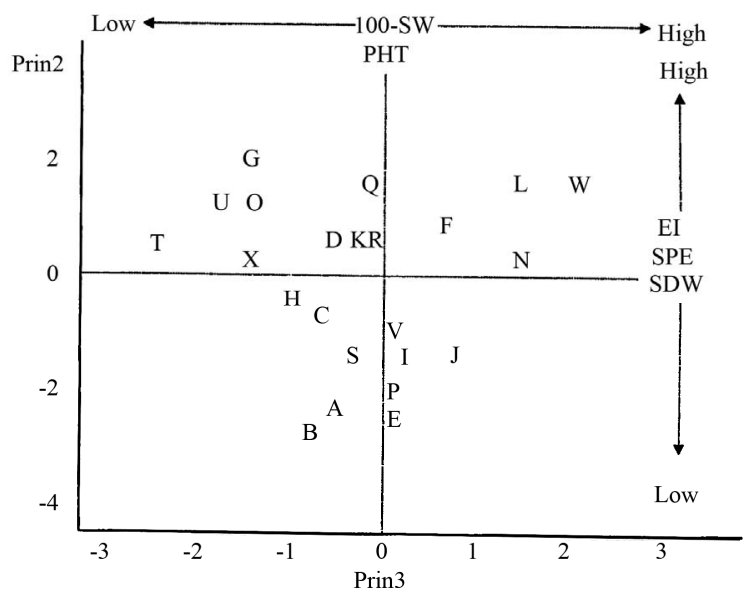

Figure 3. Biplot of the second and third principal components to show the interrelationship of seed vigour and yield traits of the 24 West African rice genotypes. Note: Letters A - $\mathrm{X}$ represent genotypes 1 to 24 .

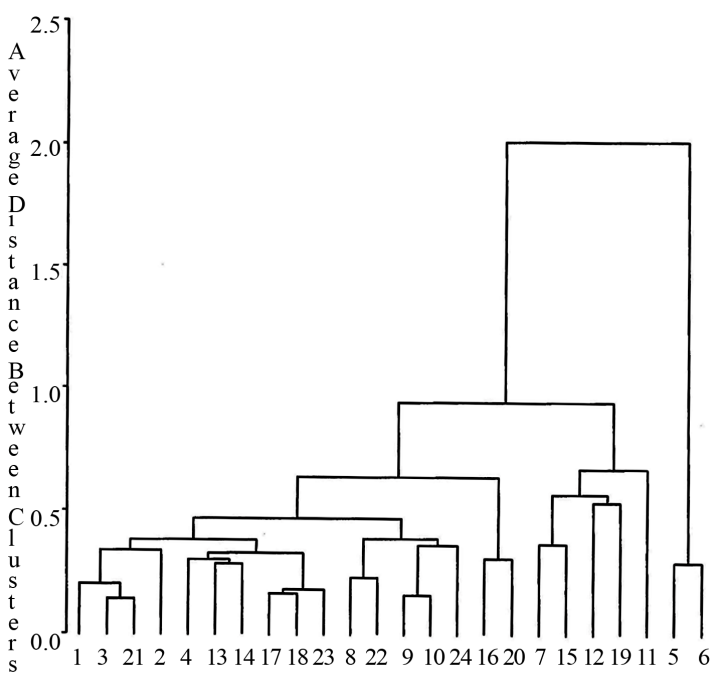

GENOTYPE

Figure 4. Classification of the 24 West African rice genotypes according to percentage germination and percentage emergence across two seasons 
(TOx 4004-43-1-2-1 and WAT 1156-B-4-2-3-3) with mean percentage germination and mean percentage emergence of $65.71 \%$ and $58.81 \%$ respectively. Five genotypes (WITA 9, WAT 1074-B-39-2-3-3, TOx 421625-2-3-1-3, TOx4303-13-3-1-2 and WITA 7) joined in group III with mean percentage germination and percentage emergence of $58.88 \%$ and $55.19 \%$ respectively. Group IV included two genotypes (WITA 1 and BW3481) and had mean percentage germination and percentage emergence of $20.11 \%$ and $29.49 \%$, respectively.

\section{Discussion}

The result of the principal component analysis substantially confirms the pattern of character covariation among the genotypes studied. It also identified the characters that contribute most to the variation within a group of entries [15]. The biological meaning of the principal components can be assessed from contribution of the different variables to each principal component according to the Eigen vectors [36]. The results of the principal component analysis show that different characters contributed differently to the total variation as indicated by their Eigen vectors as well as their weight and loading on the different principal axes. The differences in the growing conditions modulated the contributions of different characters to the total variation. Each component score obtained is a linear combination of the traits similar to an index, such that the maximal amount of variance is shown on the first principal component, second maximal amount is shown on the second component, third maximal amount is shown on the third component and so on.

The result of the PCA across the two seasons indicated that the first three axes of the PCA captured $60.47 \%$, $16.68 \%$ and $9.19 \%$ of the total variation among the entries. This is in agreement with Clifford and Stephenson [17] and Adekoya [37] who reported that the first three principal components were the most important in reflecting the variation patterns among accessions and the characters highly associated with these should be used in differentiating accessions. The PCA1 also revealed that seed vigour traits such as seedling vigour index-I, seedling vigour index-II, speed of germination index, percentage germination, seedling establishment, energy of germination, emergence percentage and seed yield/plant contributed substantially to the discrimination among the 24 genotypes.

Principal component analysis gave the distribution pattern of individual scores of the genotypes along the principal component axis and the portion of the total variance contributed by each of the different variables $[38,39]$. The clustering of scores among PC axes suggests that some relationships exist among individuals within a cluster. The main components which discrimi- nated between genotypes for PC1 (Y-axis) were seedling vigour index-I, seedling vigour index-II, percentage germination, speed of germination index, energy of germination, seedling establishment, seed yield/plant and emergence percentage and for PC2 (x-axis) were emergence index, speed of emergence and seedling dry weight. Generally, genotype BW348-1 and WITA 1 had low rating for most of the components. The other genotypes were either average (close to the zero line) or higher when above the line.

Genotypic differences in seed germination and emergence were revealed in the study and the 24 rice genotypes were divided into four distinct groups. Varietal differences in seed germination and emergence of rice have been reported by Lee et al. [26], and Adebisi et al. [40]. The classification of the genotypes into separate distinct clusters could lead to increase in heterotic effect in cross progenies. The different clusters, showed some character distinctions that could be employed for hybridization purpose. Cluster group I for instance recorded the highest emergence percentage and also had a high germination percentage. Group II also had high germination percentage with fairly high emergence percentage. Genotypes in group IV had the lowest germination percentage and emergence percentage.

\section{Conclusions}

This study, which used multivariate techniques to assess the extent of genetic variation in seed vigour and yield traits of 24 West African rice genotypes, was a first step in gaining an insight into the germplasm divergence, which is an important step towards an efficient exploitation of genetic resources of West African rice genotypes.

The principal component analysis identified speed of germination index, seedling vigour index-I, seedling vigour index-II, emergence percentage seedling establishment, percentage germination, seed yield/plant, energy of germination, seeding dry weight and plant height as characters that mainly described the variation within the rice genotypes. However, some components did not contribute appreciably to the variation within the entries and could be dropped in similar analysis, in order to improve the quality of result from the technique.

The cluster analysis classified the rice genotypes into four distinct clusters, indicating that hybridization of genotypes across clusters could lead to increase in heterosis in cross progenies. The following characters should be included in the crop improvement programme for improved seed quality within lowland rice germplasm: speed of germination index, seedling vigour index-I, seedling vigour index-II, percentage germination, percentage emergence, seedling establishment, energy of germination and seed yield/plant. 
Multivariate statistical techniques are appropriate for the classification of diversity among rice germplasm and indeed those of other crop species.

\section{REFERENCES}

[1] R. B. Cartel, "Factor Analysis: An Introduction to Essential I. The Purpose of Underlying Models," Biometrics, Vol. 21, No. 1, 1965, pp. 190-235. doi:10.2307/2528364

[2] R. Bartual, E. A. Carbonell and D. E. Green, "Multivariate Analysis of a Collection of Soybean Cultivars for Southeastern Spain," Euphytica, Vol. 34, No. 4, 1985, pp. 113-123. doi:10.1007/BF00022870

[3] O. J. Ariyo, "Measurement and Classification of Genetic Diversity in Okra (Abelmoschus esculentus)," Ann Appl. Biol, Vol. 116, No. 2, 1990, pp. 335-341. doi:10.1111/j.1744-7348.1990.tb06615.x

[4] O. J. Ariyo and A. Odulaja, "Numerical Analysis of Variation among Accessions of Okra (Abelmoschus esculentus (L.) Moench)," Annals of Botany, Vol. 67, 1991, pp. 527531.

[5] O. J. Ariyo, "Genetic Diversity in West Africa Okra (AbeImoschus caillei L. Chev.) Stevels-Multivariate Analysis of Morphological and Agronomic Characteristics," Genetic Resources and Crop Evolution, Vol. 40, No. 1, 1993, pp. 25-32. doi:10.1007/BF00053461

[6] F. Flores, J. C. Gutrerrez, J. Lopez, M. T. Moreno and J. I. Cubero, "Multivariate Analysis Approach to Evaluate a Germplasm Collection of Heydsarum coronarium L.," Genetic Resources and Crop Evolution, Vol. 44, No. 6, 1997, pp. 545-555. doi:10.1023/A:1008682019883

[7] O. K. K. Mponda, S. Morse, D. Gibbon and A. E. Arthur, "Genetic Studies on Seedling Vigour in Sesame," Annual of Applied Botany, Vol. 131, No. 1, 1997, pp. 161-170. doi:10.1111/j.1744-7348.1997.tb05403.x

[8] T. Cardi, "Multivariate Analysis of Variation among Solanum commersomi (+) S. tuberosum Somatic Hybrids with Different Ploidy Levels," Euphtica, Vol. 99, No. 1, 1998, pp. 35-41. doi:10.1023/A:1018361016968

[9] J. D. Berdahl, H. F. Mayland, K. H. Asay and P. G. Jefferson, "Variation in Agronomic and Morphological Traits among Russian Wildrye Accessions," Crop Science, Vol. 39, No. 6, 1999, pp. 1890-1895. doi:10.2135/cropsci1999.3961890x

[10] A. Nassir, "Studies on Genotype X Environment Interactions Variability and Plant Character Correlation in Rice," Ph.D. Thesis, University of Agriculture, Abeokuta, 2002, 123 pages.

[11] M. A. Adebisi, "Variation, Stability and Correlation Studies in Seed Quality and Yield Components of Sesame (Sesamum indicum L.)," Unpublished Ph.D. Thesis, University of Agriculture, Abeokuta, 2004, 122 pages.

[12] M. A. Adekoya, M. A. Adebisi, A. M. Abdul-Rafiu and J. O. Amira, "Effect of Genotype and Seed Production Environment on Growth and Seed Yield Characters of Twenty Okra (Abelmoschus esculentus, L.)," Proceedings of the 34th Annual Conference of the Genetics Society of
Nigeria (GSN), Ibadan, 19-24 September 2010, pp. $137-$ 146.

[13] O. J. Ariyo, "Multivariate Analysis and Choice of Parents Hybridization in Okra (Abelmoschus esculentus L.)," Theoretical and Applied Genetics, Vol. 74, No. 3, 1987, pp. 361-363. doi:10.1007/BF00274718

[14] N. V. Nair, R. Balakrishan and T. V. Screenivasan, "Variability for Quantitative Traits in Exotic Hybrid Germplasm of Sugarcane," Genetic Resources and Crop Evolution, Vol. 45, No. 5, 1998, pp. 459-464. doi:10.1023/A:1008696617524

[15] B. A. Ogunbodede, "Multivariate Analysis of Genetic Diversity in Kenaf (Hibiscus cannabinus L.)," African Crop Science Journal, Vol. 5, No. 2, 1997, pp. 127-133.

[16] H. H. Hayman, "Modern Factor Analysis," 2nd Edition, University of Chicago Press, Chicago, 1967.

[17] H. T. Clifford and W. Stephenson, "An Introduction to Numerical Classification," Academy Press, London, New York, 1975, 229 pages.

[18] A. M. Rhodes and F. W. Martins, "Multivariate Studies of Variation in Yams (Dioscorea alata L.)," Journal of American Society of Agricultural Science, Vol. 97, 1972, pp. 685-688.

[19] M. O. Akoroda, "Principal Component Analysis and Metroglyph of Variation among Nigerian Yellow Yam," Euphytica, Vol. 32, No. 2, 1983, pp. 565-573. doi:10.1007/BF00021469

[20] K. O. Omokhafe and J. E. Alika, "Multivariate of Agronomic Data on Hevea brasiliensis," Proceeding of SUSANIBS Meeting, Ibadan, 23-27 August 1999, pp. 168-173.

[21] J. Vadeveloo, "The Use of Multivariate Statistics to Evaluate the Response of Rice Straw Varieties to Chemical Treatment," Australian Journal of Agricultural Science. (Ajas), Vol. 91, pp. 83-89.

[22] O. J. Ariyo, "Measurement and Classification of Genetic Diversity in Okra (Abelmoschus esculentus)," Annals of Applied Biology, Vol. 116, No. 2, 1999, pp. 335-341. doi:10.1111/j.1744-7348.1990.tb06615.x

[23] D. C. A. Akintobi, M. A. Adebisi and D. K. Ojo, "Multivariate Analysis of Phenetic Similarity of Cowpea Genotypes in Different Agro-Ecological Zones," Nigerian Journal of Ecology, Vol. 4, No. 1, 2002, pp. 18-23.

[24] Patterson and Weatherup, "Statistical Criteria for Distinctness between Varieties of Hebage Crops," Journal of Agricultural Science, Vol. 102, 1994, pp. 59-68.

[25] J. E. Alika, "Principal Component Analysis and Metroglyph of Variation among Nigeria Yellow Yams," Eyphytica, Vol. 32, 1991, pp. 363-373.

[26] S. V. Lee, J. H. Lee and T. O. Kwon, "Varietal Differences in Seed Germination and Seedling Vigour of Korean Rice Varieties Following Dry Heat Treatment," Seed Science and Technology, Vol. 30, 2001, pp. 311-321.

[27] ISTA, "International Rules for Seed Testing," Seed Science and Technology, Vol. 13, 1985, pp. 307-513.

[28] AOSA, "Seed Vigour Testing Handbook. Contribution No. 32 to the Handbook on Seed Testing," Association of 
Official Seed Analysis, 1983.

[29] R. P. S. Kharb, B. P. S. Lather and D. P. Deswal, "Prediction of Field Emergence through Heritability and Genetic Advance of Vigour Parameters," Seed Science and Technology, Vol. 22, 1994, pp. 461-466.

[30] S. Ruan, Q. Xue and K. Tylkowska, "The Influence of Priming on Germination of Rice (Oryza sativa L.) Seeds and Seedling Emergence and Performance in Flooded Soil," Journal of Seed Science and Technology, Vol. 30, 2002, pp. 61-67.

[31] P. E. S. mith and A. H. Millet, "Germinating and Sprouting Response of the Tomato at Low Temperatures," Proceeding of the American Society for Horticultural Science, Vol. 84, 1964, pp. 482-484.

[32] J. J. Mock and J. A. Eberhart, "Cold Tolerance of Adapted Maize Populations," Crop Science, Vol. 16, No. 2, 1972, pp. 230-469. doi:10.2135/cropsci1976.0011183X001600020016x

[33] M. Dadlani and D. V. Seshu, "Effects of Wet and Dry Heat Treatment on Rice Seed Germination and Seedling Vigour," International Rice Research Newsletter, Vol. 15, 1990, pp. 21-22.

[34] M. Yamauchi and T. Winn, "Rice Seed Vigour and Seedling Establishment in Anaerobic Soil," Crop Science, Vol. 36, No. 3, 1996, pp. 680-686.
doi:10.2135/cropsci1996.0011183X003600030027x

[35] A. A. Raji, "Assessment of Genetic Diversity and Heterotic Relationships in African Improved and Local Cassava (Manihot esculenta Crantz) Germplasm," Ph.D. Thesis, Obafemi Awolowo University, Ile Ife, 2003, 120 pages.

[36] A. F. Lezzoni and M. P. Pritts, "Application of Principal Component Analysis to Horticultural Research," Hort Science, Vol. 26, No. 4, 1991, pp. 334-338.

[37] M. A. Adekoya, "Evaluation of Variation, Inter-Character Correlation and Performance of Okra (Abelmoschus esculentus)," MA Dissertation, University of Agriculture, Abeokuta, 2008, 111 pages.

[38] P. M. Sneath and R. P. Sokai, "Numerical Taxonomy. The Principle and Practice of Numerical Classification," WH Freeman, San Francisco, 1973.

[39] R. Grittins, "The Application of Ordination Techniques," In: E. H. Bryanf and W. R. Atchley, Eds., Multivariate Statistical Methods, Hutchinson \& Ross, Inc., Stroudsbury, 1975, pp. 102-131

[40] M. A. Adebisi, T. A. Adeniyi, M. O. Ajala and D. C. Akintobi, "Varietal Differences in Seed Physiological Quality of West African Rice Varieties after Dry Heat Treatment," Nigerian Agricultural Journal, Vol. 39, No. 2, 2008, pp. 159-169. 